\title{
Modelo cirúrgico de insuficiência renal crônica. Estudo em coelhos
}

\section{Surgical model of chronic renal failure. Study in rabbits}

\author{
Andrei Ferreira Nicolau da Costa ${ }^{1}$; Lara de Paula Miranda Pereira²; Manoel luiz Ferreira 3; Paulo Cesar Silva ${ }^{4}$; \\ Vera lucia Antunes Chagar ${ }^{5}$; Alberto Schanaider TCBC- RJ6
}

\section{R E S U M O}

\begin{abstract}
Objetivo: Estabelecer um modelo de insuficiência renal crônica (IRC) em coelhos, com perspectivas de seu uso para ações terapêuticas e reparadoras. Método: Foram utilizados 19 coelhos da linhagem Nova Zelândia, machos, adultos, aleatoriamente distribuídos em três Grupos: Grupo 1 - Controle $(n=5)$, Grupo 2- Simulação $(n=7)$, Grupo 3 - Experimental $(n=7)$. Os animais foram anestesiados com Cetamina e Diazepam e Fentanil por via intramuscular e Sevorane, através de vaporizador. No Grupo 3 realizou-se uma nefrectomia bipolar esquerda e após quatro semanas, uma nefrectomia direita. Todas as amostras do parênquima renal foram pesadas. O Grupo 2 foi submetido a duas laparotomias, sem nefrectomia.. Em todos os grupos foram realizadas avaliações: bioquímicas com dosagens de uréia, creatinina, sódio e potássio; ultra-sonográficas abdominais; cintigráficas e histológicas. Resultados: No Grupo 3 houve aumento progressivo da uréia $(p=0.0001)$, creatinina $(p=0,0001)$, sódio $(p=0,0002)$ e potássio $(p=0,0003)$. A comparação destes resultados com os dos Grupos 1 e 2, nos diversos intervalos, também revelou elevação sérica, com significância estatística $(p<0,05)$. A ultra-sonografia identificou aumento do rim esquerdo no grupo 3, após 16 semanas. A cintigrafia comprovou, na $4^{a}$ semana, perda de 75\%da massa renal esquerda. No Grupo 3, a avaliação histológica evidenciou fibrose subcapsular e intersticial e regeneração tubular. Conclusão: O modelo experimental de IRC é exeqüível, com sobrevida dos animais, em médio prazo, o que permite o uso deste intervalo como janela terapêutica para testar diferentes ações reparadoras ao parênquima renal comprometido.
\end{abstract}

Descritores: Modelos animais. Cirurgia. Insuficiência renal. Doença crônica. Coelhos.

\section{INTRODUÇÃO}

D efine-se a insuficiência renal crônica (IRC) como uma síndrome clinica caracterizada pela perda progressiva da função renal, com um declínio da taxa de filtração glomerular e aumento das escórias nitrogenadas, decorrentes de alterações morfológicas evolutivas irreversíveis do parênquima renal ${ }^{1,2}$.

As manifestações da IRC ocorrem quando há perda da função com o comprometimento de 65 a $75 \%$ dos nefrons. Em algumas espécies, até mesmo na presença de $75 \%$ de nefrons não funcionais, a creatinina e a uréia séricas podem apresentar valores normais ou próximo da normalidade, o que acarreta grande dificuldade para elaboração de modelos experimentais capazes de reproduzir a $\operatorname{IRC} C^{1,2,3}$.

Alguns modelos experimentais utilizam intervenções cirúrgicas no intuito de causar a IRC. Em ratos encontra-se, com freqüência, vasta literatura sobre o assunto, dentre as quais sobressaem aquelas que preconizam nefrectomias em diferentes proporções, com predomino de ressecções $4 / 5$ ou 5/6, e a obstrução ureteral. Todavia, a sobrevida dos animais é muito reduzida e há de se considerar, ainda, a limitação imposta pelo volume sanguíneo circulante que interfere com a coleta de amostras para exames laboratoriais seriados. Ademais, cita-se a dificuldade para se empreender exames por métodos de imagem em face do tamanho do rato, ou camundongo e da pouca adequação do equipamento, em geral utilizado para espécies de maior porte ${ }^{4-14}$ O coelho oferece, neste cenário, melhor perspectiva na elaboração do modelo experimental com redução de massa renal e que visam causar IRC, em face de seu tamanho, volemia e aspectos morfofuncionais, que se assemelham ao anima nobile. Porém, são muito raros os artigos científicos que integram estudos em coelhos à IRC $1,2,15-17$.

Este estudo tem como objetivo estabelecer um modelo de insuficiência renal crônica em coelhos e que faculte a utilização de janela terapêutica, sem que o animal vá ao óbito e permita o acompanhamento evolutivo, com perspectivas de uso do modelo para ações terapêuticas e reparadoras.

Trabalho realizado no Centro de Cirurgia Experimental e Programa de Pós-Graduação do Departamento de Cirurgia, da Faculdade de Medicina da Universidade Federal do Rio de Janeiro.

1. Aluno de Mestrado do Programa de Pós-Graduação do Departamento de Cirurgia, da FM/UFRJ, RJ, BR; 2. Aluna do Curso de Graduação e Bolsista FAPERJ - FM/UFRJ, RJ, BR; 3. Aluno de Doutorado, do Programa de Pós-Graduação do Departamento de Cirurgia FM/UFRJ, RJ, BR; 4. Professor Adjunto do Departamento de Cirurgia - FM/UFRJ, RJ, BR; 5. Professora Assistente do Departamento de Patologia - FM/UFRJ, RJ, BR; 6. Coordenador do Programa de Pós-Graduação do Departamento de Cirurgia - FM/UFRJ, RJ, BR. 


\section{MÉTODO}

O projeto foi aprovado pelo Comitê de Ética para o Uso de Animais de Laboratório em Pesquisa, Ensino e Extensão, da Faculdade de Medicina da Universidade Federal do Rio de Janeiro, n²1/05 e segue os critérios internacionais recomendados.

Foram utilizados 19 coelhos (Orictolagus cunniculus) da linhagem Nova Zelândia, machos, adultos, obtidos em criadouro único, com peso variando entre 2 a 3 $\mathrm{kg}$, mantidos em gaiolas individuais, em ambiente com exaustão e ventilação constantes e temperatura apropriada, com água ad libitum e ração industrial.

Todos os animais receberam penicilina 40.000 IU/kg, duas horas antes do procedimento cirúrgico.

A medicação pré-anestésica foi administrada por via intramuscular, com Cetamina $(10 \mathrm{mg} / \mathrm{kg})$, Diazepam $(0,5 \mathrm{mg} / \mathrm{kg})$ e Fentanil $(0,005 \mathrm{mg} / \mathrm{kg})$. Para a indução e manutenção anestésicas foram utilizados $6 \mathrm{~mL}$ de Sevoflurano em vaporizador, com oxigênio a 100\%, em circuito aberto. Manteve-se analgesia pré-empitiva com $5 \mathrm{mg}$ de Cloridrato de tramadol intra-muscular. Durante todo o procedimento cirúrgico, os animais estiveram acomodados em colchão térmico e foram monitorados com oxímetro.

Constituíram-se três grupos, por distribuição randomizada: Grupo 1 - Controle, composto por cinco animais $(n=5)$; Grupo 2- Simulação com sete animais $(n=7)$ e Grupo 3 - Experimental, também com sete animais $(n=7)$.

Os Grupos Simulação e Experimental foram igualmente submetidos aos procedimentos anestésicos, tricotomia do flanco, anti-sepsia com iodo-povidona, colocação dos campos cirúrgicos. Seguiram-se a laparotomia no flanco esquerdo realizada por incisão longitudinal de $5 \mathrm{~cm}$, a dissecção do subcutâneo e dos músculos parietais até a exposição da cavidade abdominal e acesso a loja renal esquerda. Assim, depois de removida toda a gordura peri-renal esquerda, prosseguiu-se com a colocação de um clampe vascular no pedículo renal ipsilateral, com duração de 15 minutos. No Grupo 3, aduziu-se, mediante uma incisão transversa em cunha, a ressecção dos dois pólos renais, acompanhada de suturas das áreas cruentas com fio monofilamentar absorvível 2-0, com pontos em " $x$ " e remoção do clampe vascular para revisão da hemostasia. O tempo cirúrgico destes procedimentos, no Grupo 3, foi de aproximadamente 15 minutos. A síntese da ferida operatória se fez por planos, com sutura contínua com fio poligalactina 910, 2-0. A síntese de pele foi feita com fio de nylon monofilamentar 3-0, em pontos separados. Os fragmentos renais retirados foram pesados e colocados em formol a 10\%.

Após quatro semanas de pós-operatório, os animais dos grupos Simulação e Experimental foram reoperados. No Grupo 3 realizou-se nefrectomia direita, com os mesmos cuidados anestésicos e cirúrgicos descritos anteriormente e o rim foi pesado. No Grupo 2 foi efetuada apenas laparotomia com clampeamento do pedículo renal direito, por 10 minutos.

Em todos os grupos foram realizados testes bioquímicos, com dosagens de uréia, creatinina, sódio e potássio, no pré-operatório, 24 após a nefrectomia direita ( $4^{\mathrm{a}}$ semana), na oitava e $16^{\mathrm{a}}$ semana. Aduziu-se, ainda, estudo ultra-sonográfico abdominal na primeira, quarta, oitava e $16^{\mathrm{a}}$ semanas.

Realizou-se, ainda, estudo cintigráfico com ácido dimercaptossuccinico (DMAS) na primeira e quarta semanas, em todos os grupos. Nos animais submetidos à nefrectomia polar, este exame precedeu a retirada do rim contralateral.

$\mathrm{Na} 16^{\mathrm{a}}$ semana todos os animais foram submetidos à eutanásia, por sobredose anestésica e então se procedeu à retirada de ambos os rins, nos Grupos 1 e 2 e do remanescente, no Grupo 3, acrescido da avaliação do peso renal.

Para os estudos histopatológico empreendeu-se análise das amostras previamente incluídas em blocos de parafina e submetidas a cortes com $5 \mathrm{~mm}$, coradas por HematoxilinaEosina (HE). As preparações histológicas foram avaliadas em aumentos de 250 e 400 vezes. Os critérios da avaliação, efetuada por um único observador, basearam-se na ocorrência de lesões inflamatórias, regenerativas ou de morte celular.

Os resultados foram analisados pelos seguintes métodos estatísticos: testes de Dunn (TD), Kruskal Wallis (TKW), Freidman (TF), considerando-se os resultados significantes para valores de $p<0,05$.

\section{RESULTADOS}

Durante todo experimento não houve óbitos.

No Grupo 3 - Experimental, a avaliação bioquímica mostrou uma queda progressiva da função renal, após a nefrectomia contra lateral ( $4^{\mathrm{a}}$ semana), até a $16^{\circ}$ semana, com um aumento significante da creatinina ( $p=0,0001)$, uréia ( $p=0,0001)$, potássio $(p=0,0003)$ e sódio $(p=0,0002)$ em cada animal estudado (Figura 1).

Na comparação entre os grupos houve elevação progressiva da creatinina, no Grupo 3 (Experimental), com significância estatística, na quarta $(p<0,0043)$, oitava $(p<0,0017)$ e $16^{a}$ semana $(p<0,0012)$. O mesmo foi observado com a uréia para quarta $(p<0,0005)$, oitava e $16^{\mathrm{a}}$ semanas $(p<0,001)$. A comparação entre os grupos no que tange ao sódio, revelou aumento sérico, no Grupo 3, mais discreto na quarta $(p<0,0153)$ e oitava semanas $(p<0,0299)$ e mais acentuado na $16^{a}$ semana $(p<0,0018)$. Verificou-se, também, a elevação do potássio no Grupo 3 - Experimental quando comparado aos demais grupos, apenas na oitava $(p<0,0064)$ e $16^{a}$ semanas $(p<0,001)$, (Figura 2$)$.

No Grupo 3 - Experimental, a ultrasonografia do rim direito dos animais com nefrectomia bipolar não revelou aumento de tamanho. Já o rim esquerdo revelou-se aumentado na oitava semana, padrão este que se manteve na $16^{a}$ semana $(p<0,001)$ (Figura 3$)$. A comparação no Grupo 3 - Experimental entre o peso estimado do rim esquerdo após a nefrectomia bipolar e o encontrado na $16^{\mathrm{a}}$ semana evidenciou aumento significante $(p<0,0003)$, (Figuras 3 e 4).

A cintigrafia, associada ao marcador com radioisótopo (DMSA), atestou a presença de $25 \%$ de mas- 

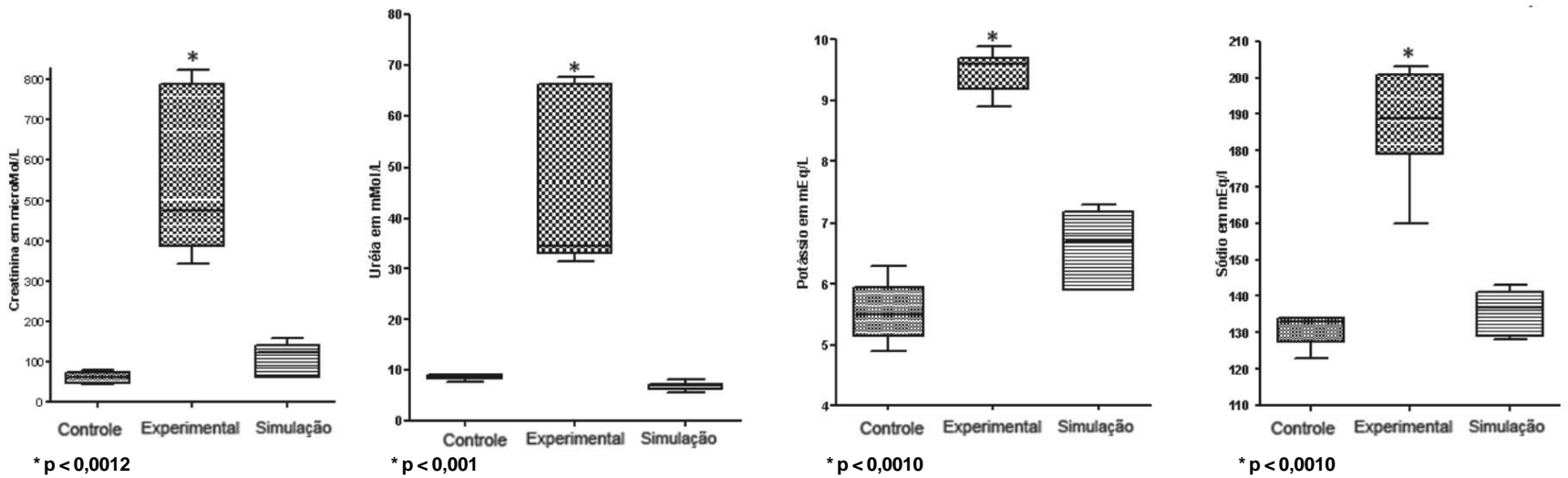

Figura 1 -Avaliações bioquímicas da creatinina, uréia, potássio e sódio, dos grupos controle, experimental e simulação na 16 semana.

sa renal esquerda remanescente, durante a quarta semana, após a nefrectomia bipolar (Figura 5) e foi possível observar que o rim direito apresentou aumento compensatório da função, se comparado aos padrões pré-operatórios. Nos Grupos 1 - Controle e 2 - Simulação observou-se distribuição eqüitativa do DMSA (Figuras 3 e 5 ).

A avaliação microscópica do Grupo 1 - Controle não demonstrou presença de alterações em ambos os rins.
No Grupo - 2 Simulação foi evidenciado, no rim direito, discretos focos de nefrite intersticial mononuclear/mista na zona medular, mesmos achados do rim esquerdo, acrescidos deste padrão também no córtex. No rim esquerdo, além destes achados encontrou-se, ainda, a presença de leve inflamação mononuclear na gordura do hilo renal e junto ao epitélio de transição da pelve. No Grupo 3 - Experimental não foram evidenciadas alterações significativas dos frag-
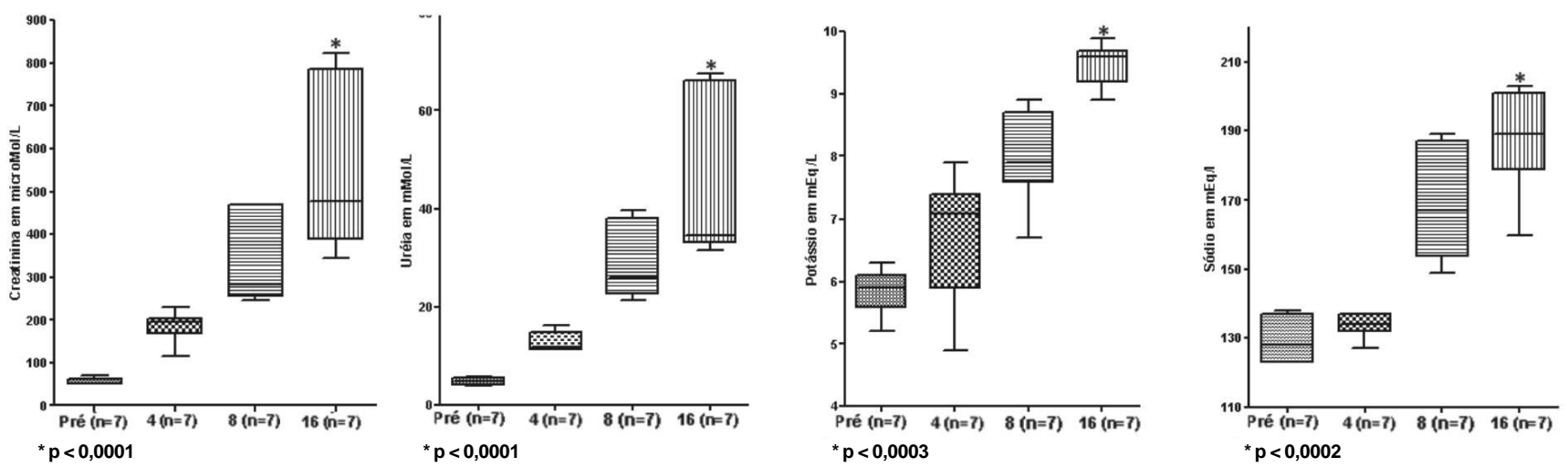

Figura 2 -Avaliações bioquímicas da creatinina, uréia, potássio e sódio, do grupo experimental, no pré-operatório, 4, 8 e 16 semanas.
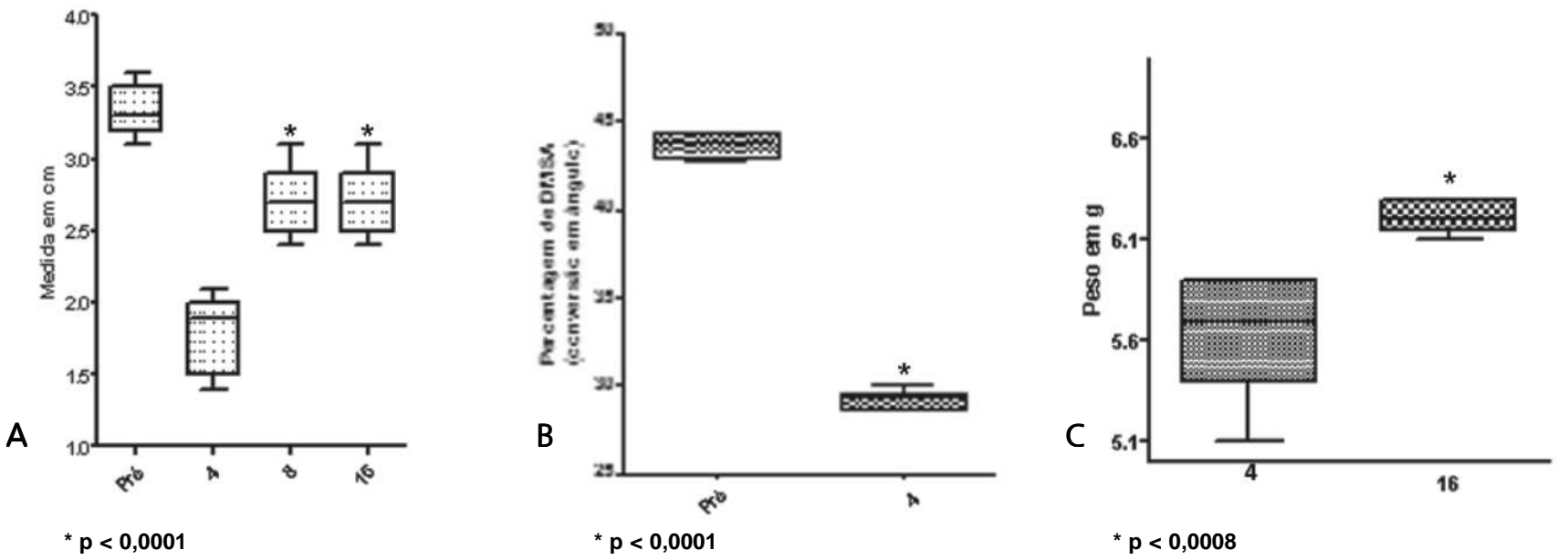

Figura 3 -A. Avaliação ultrassonográfica do rim esquerdo nos momentos pré e 4, 8 e 16 semanas do grupo experimental; B. Percentagem DMSA do rim esquerdo do grupo experimental durante o pré-operatório e a $4^{a}$. semana após a nefrectomia bipolar; $\boldsymbol{C}$. Peso do rim esquerdo do grupo experimental na $1^{\text {a. }}$ e $16^{a}$ semana. 


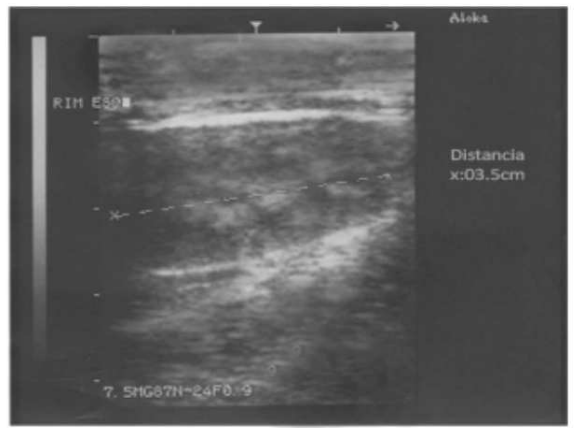

Ultra sonografia do rim ı esquerdo (grupo 3), no pré-operatório medindo $3,5 \mathrm{~cm}$

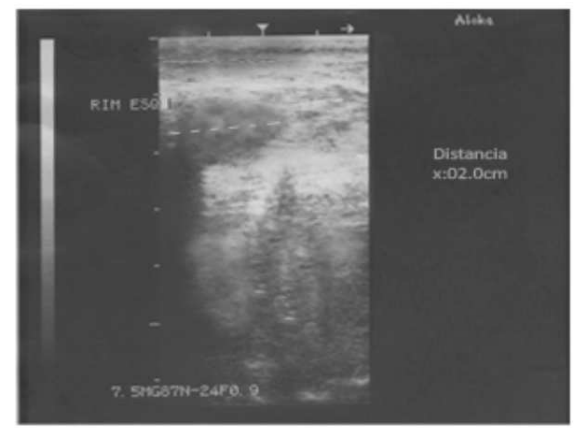

Ultra sonografia do rim I esquerdo (grupo 3), na $4^{\text {a }}$ semana após nefrectomia bipolar medindo $2,0 \mathrm{~cm}$

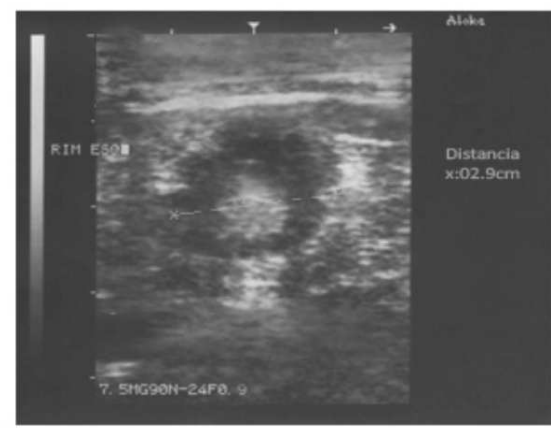

Ultra sonografia do rim esquerdo (grupo 3 ), com 16 semanas medindo $2,9 \mathrm{~cm}$

Figura 4
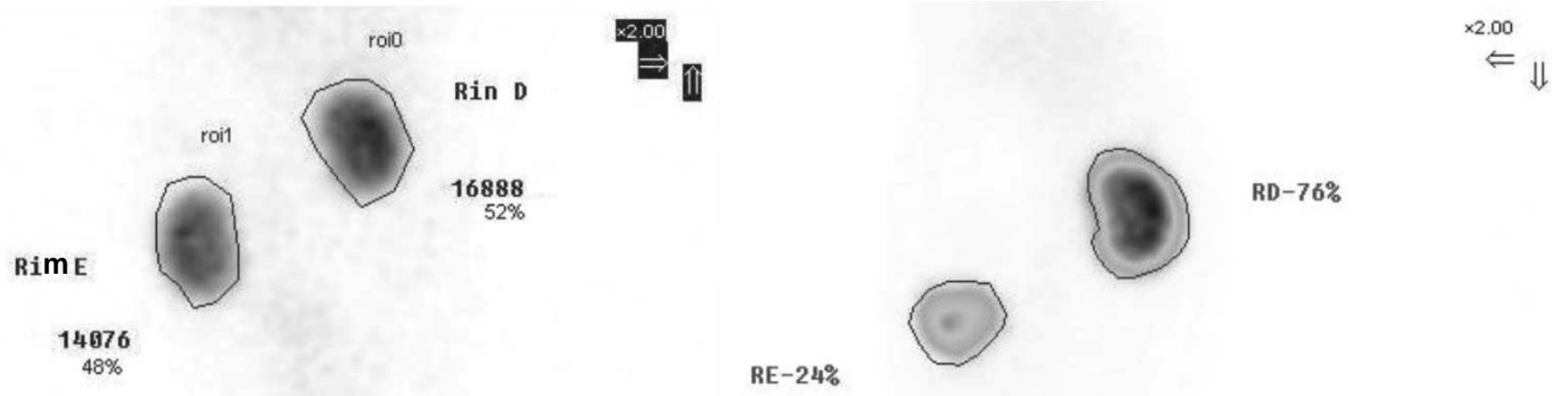

Figura 5 - Cintigrafia do grupo experimental com o animal em decúbito ventral, nos tempos pré-operatório 4a. semana após a nefrectomia bipolar esquerda quantificando a massa renal nos diferentes tempos.

mentos dos pólos renais removidos na primeira semana. 0 rim contralateral removido na quarta semana apresentou moderada congestão medular e discretos focos de nefrite intersticial. Na $16^{a}$ semana, foi evidenciada fibrose subcapsular, mais acentuada nas porções remanescentes contíguas aos pólos renais. Nos locais em que a fibrose foi mais intensa houve, adicionalmente, hemorragia e dilatação de túbulos renais ou ductos coletores. Verificaram-se, também, moderada fibrose intersticial, espessamento e mineralização de membranas basais de túbulos renais, da cápsula de Bowmann e infiltrado de alguns túbulos e glomérulos, principalmente no córtex e na região córticomedular (formando larga faixa em forma de cúpula na re- gião cortical). A mineralização na medular foi bem mais leve. Houve aumento do infiltrado em alguns glomérulos com dilatação da cápsula de Bowmann, deformidade, destruição e fibrose (esclerose) glomerulares. Outros glomérulos encontravam-se atróficos, ou apresentavam maior celularidade. Em alguns túbulos notou-se a formação de cilindros hialinos. Houve evidente regeneração tubular caracterizada por proliferação de túbulos revestidos por células epiteliais planas (achatadas), com núcleos hipercromáticos. Em alguns locais, as células proliferadas agrupavam-se com formação de estruturas semelhantes as tubulares, porém sem lúmen. Ademais, foram encontrados grupos de túbulos contornados com tumefação e

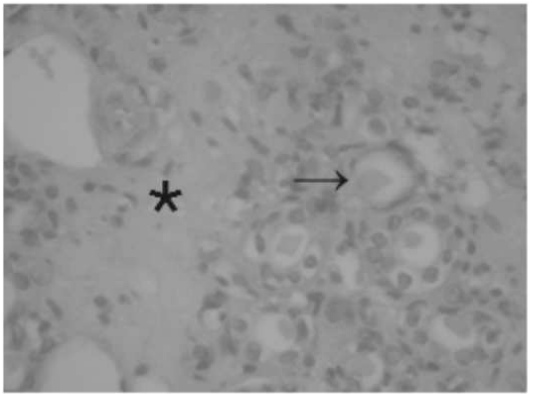

Fibrose intersticial $\left(^{*}\right)$ e cilindros hialinos (->). HE x 250.

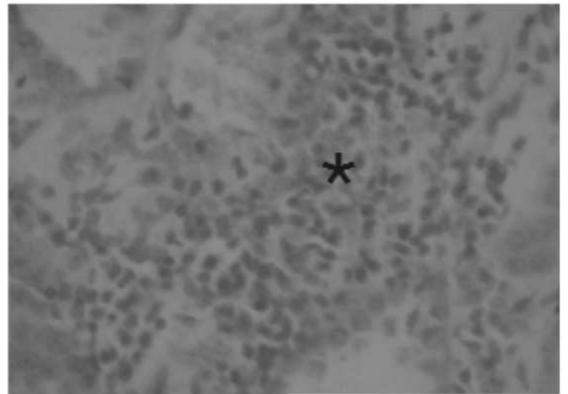

Nefrite túbulointersticial - infiltrado inflamatório mononuclear $\left({ }^{*}\right)$. HE x 250.

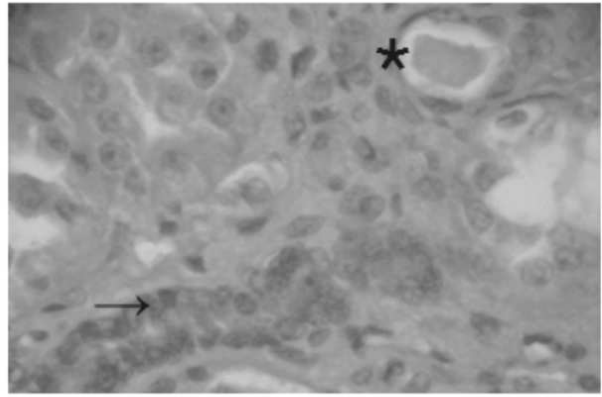

Epitélio tubular com padrão regenerativo $(->)$; cilindro hialino $\left({ }^{*}\right)$. HE x 400.

Figura 6 
vacuolização citoplasmática, com evolução para lise de células epiteliais. Adicionalmente, houve leve infiltração inflamatória por células mononucleares e alguns neutrófilos e eosinófilos na cápsula e gordura peri-renal, discreta nefrite intersticial mononuclear multifocal e presença de pigmento acastanhado no citoplasma de algumas células tubulares (Figura 6).

\section{DISCUSSÃO}

No final da década de 50 e início da de 60 surgiram os primeiros modelos experimentais confiáveis para o estudo da insuficiência renal crônica. A partir deste período, os efeitos da nefrectomia subtotal, com massa residual de $5 / 6$ ou $4 / 5$ de todo o parênquima, se avolumaram, abrindo novas perspectivas para padronização dos modelos experimentais cirúrgicos. Porém, a utilização de ratos e camundongos impõe algumas limitações quanto à extração seriada de sangue para dosagens laboratoriais. Há o risco de redução acentuada da volemia, com o comprometimento da integridade destes animais. Ademais, os métodos de imagem, na grande maioria das vezes, são efetuados em aparelhos destinados aos seres humanos, o que dificulta a avaliação. Em face destas restrições, buscou-se um animal que permitisse não só a realização de exames bioquímicos com mais freqüência em função de um volume sanguíneo maior e sem risco a sobrevida do mesmo e cuja manipulação para estudos de imagem, a exemplo da cintigrafia, fosse mais exeqüível. A possibilidade de deslocamento destes animais sem grandes contratempos, ou a ausência de logística complexa para a sua manutenção são outras vantagem da escolha dos coelhos. Ressalta-se, contudo, a escassez de modelos experimentais de IRC nestes animais, que sirvam de base para comparações com a pesquisa ora desenvolvida $a^{1,2,4,7}$.

O procedimento cirúrgico para a obtenção da IRC em coelhos foi realizado em dois tempos, ou seja, na primeira e quarta semanas. Esta estratégia é vital para permitir a sobrevida dos animais, porquanto a retirada inicial dos pólos renais, unilateralmente, viabilizou a adaptação do animal para uma nova intervenção, desta feita mais extensa. A tentativa de se empreender os dois procedimentos em um só tempo cirúrgico resulta em taxa de mortalidade proibitiva, com óbito de cerca de $80 \%$ dos coelhos no pósoperatório imediato, ou na primeira semana após o ato cirúrgico ${ }^{4}$.

Após a nefrectomia bipolar esquerda, a cintigrafia com o ácido dimercaptossuccinico (DMSA) realizada na quarta semana, evidenciou, como esperado, uma área maior de captação no rim direito e comprovou a existência de apenas 24 a $25 \%$ de parênquima à esquerda, ou seja, sem evidência de aumento de volume deste rim, após a primeira operação. O DMSA se liga ao citoplasma das células tubulares convolutas proximais e delineia a imagem do córtex renal| ${ }^{15}$. A quantificação da massa renal por este método requer a presença de parte ou totalidade de am- bos os rins haja vista que o programa computacional, ao analisar os resultados, demarca as áreas existentes, bilateralmente, e as afere de forma comparativa. Deste modo, não foi possível efetuar novos exames com este radioisótopo, após a nefrectomia direita. Ressalta-se que, o uso deste parâmetro não foi encontrado na literatura consultada (bancos de dados Lilacs, Scielo e PubMed). Portanto, considerando a presença de uma massa residual de $25 \%$ do rim esquerdo, pode-se afirmar que, na quarta semana, a ressecção compreendeu quase $88 \%$ de todo o parênquima de ambos os rins (nefrectomia 7/8), ou seja, um procedimento mais extenso do que a nefrectomia $5 / 6$, na qual se retira pouco mais de $83 \%$ da massa total renal bilateral.

Os pólos retirados e pesados foram confrontados com o resultado da cintigrafia e houve similaridade entre os achados, caracterizada pela retirada de $75 \%$ da massa renal. Assim, no que diz respeito ao cálculo do peso da massa renal esquerda remanescente após nefrectomia bipolar na primeira semana, este valor foi estimado mediante apuração da média dos pesos do rim esquerdo dos Grupos 1 e 2, da qual se subtraiu à média obtida do peso dos pólos retirados. O resultado encontrado, que permaneceu inalterado até a quarta semana, foi comparado com aquele obtido após o computo da média dos pesos do rim esquerdo residual, retirado com 16 semanas. Observou-se, então aumento do peso renal esquerdo ao final do experimento. A ultrasonografia também revelou aumento do tamanho dos rins remanescentes dos coelhos, com 16 semanas e ambas as ocorrências (aumento de peso e tamanho) sinalizaram a presença de fenômenos regenerativos (Figura 3). Kim utilizou o modelo 5/6 nefrectomia e observou aumento na taxa de filtração glomerular em 24 semanas após o procedimento cirúrgico ${ }^{10}$. Atribuiu o fato à hipertrofia compensatória Este achado foi descrito por outros autores, em ratos submetidos à nefrectomias unilaterais e bilaterais parciais, em períodos que variam de quatro a oito semanas $^{19}$. Todavia, nesta pesquisa empreendida com os coeIhos, a regeneração parenquimatosa não foi suficiente para determinar recuperação funcional concomitante. Dados observados por diversos autores corroboram com os resultado do presente estudo ${ }^{9,10,16,18,19}$.

Kaufman et al. , já relatavam, em ratos, a compensação adaptativa da função renal após a ablação parcial em dois tempos cirúrgicos, com intervalo de três semanas. Este detalhe possibilitou a execução do modelo com a redução do número de óbitos, à semelhança dos achados aqui apresentados com os coelhos. Estes autores descreveram um período de aumento da uréia nos primeiros dias, e que se seguia por um intervalo de estabilidade até que a nefrectomia contralateral fosse efetuada, quando então, havia aumento progressivo deste metabólito. Esta ocorrência não foi verificada no presente estudo, posto que o foco de interesse foi avaliar a instalação concreta de um quadro de IRC e que não ocorreria antes da nefrectomia direita. Logo, as avaliações bioquímicas não compreenderam o intervalo entre as nefrectomias bipolar esquerda e direita, mas um período de 13 semanas, iniciado na quarta sema- 
na, no qual se observou aumento progressivo dos compostos nitrogenados, do sódio e do potássio, este último, a partir da oitava semana ${ }^{5-7}$. Ao considerar-se a expectativa de vida de um coelho em torno de sete a oito anos, ou seja, aproximadamente dez vezes menor do que a dos seres humanos, pode-se, analogamente, supor que o intervalo de observação dos animais com o quadro de IRC, neste estudo, estendeu-se por período correspondente a cerca de dois anos e meio de vida em anima nobile,

A elevação das escórias nitrogenadas e do sódio e potássio no grupo 3 -Experimental nos diversos períodos evolutivos, e na comparação destes resultados com os Grupos 1- Controle e 2 - Simulação comprovaram o dano renal instalado a partir da quarta semana e que progrediu até a 16 a semana. O período mais uniforme cujos valores expressaram a IRC se deu nas últimas nove semanas do experimento (Figuras 1 e 2).

No Grupo 3 - Experimental, a associação de resultados das dosagens bioquímicas com o estudo histológico foi fundamental para o diagnóstico de insuficiência renal crônica ${ }^{12-16,20-23}$. As alterações histológicas encontradas no Grupo 2- Simulação, a exemplo do discreto foco de nefrite intersticial, assim como a leve inflamação mononuclear na gordura do hilo renal junto ao epitélio de transição podem ser atribuídas ao trauma cirúrgico e a isquemia de 15 minutos aplicada ao pedículo renal esquerdo. No Grupo 3 - Ex- perimental, as características mais marcantes e que caracterizam a cronicidade das lesões foram: a fibrose subcapsular intersticial, a dilatação de túbulos renais ou ductos coletores e glomérulos com dilatação e áreas de escleroses, mineralização de membranas basais de túbulos renais $^{11-17}$ (Figura 6). Estudos com ratos evidenciaram na nefrectomia subtotal unilateral e total contralateral aumento da pressão capilar glomerular capaz de causar proteinúria e insuficiência renal progressiva ${ }^{19}$. Isto se deve à esclerose focal e segmentar, também observada nos animais do Grupo 3. A glomeruloesclerose, a atrofia tubular proximal e o aumento a apoptose são os achados mais freqüentes na IRC, sendo provável que fibrose túbulo-intersticial e a inflamação contribuam para a falência dos nefrons ${ }^{1-3,9,10,13,14}$. Descartou-se a possibilidade do fio cirúrgico utilizado ter causado anormalidades ao exame, haja vista sua absorção ocorrer em período máximo de três a quatro semanas. A regeneração tubular observada com 16 semanas comprovou a tentativa do organismo em promover a recuperação do rim remanescente e que de fato aumentou de tamanho e peso, mas não o bastante para determinar melhora funcional.

O modelo experimental de IRC em coelhos é exeqüível, com sobrevida dos animais, em médio prazo, o que permite o uso deste intervalo como janela terapêutica para ações reparadoras ao parênquima comprometido.

\title{
A $B$ S S T $R$ R A C C T
}

\begin{abstract}
Objectives: To establish a model of chronic renal failure in rabbits, with perspectives of its use for therapeutic and repairing actions. Methods: Nineteen males, adults rabbits (New Zealand) randomly distributed into three groups were used: Group 1 - Control (n =5); Group 2-Sham $(n=7)$; and Group 3 - Experimental $(n=7)$. They were anaesthetized by using intramuscular Cetamine, Diazepam and Fentanyl followed by Sevorane with vaporizer device. In Group 3, a bipolar left nephrectomy was carried out and after four weeks, it was also done a right nephrectomy. All the samples of the renal tissue were weighed. The Group 2 was only submitted to both abdominal laparotomies, without nephrectomy. Biochemical evaluations, with urea, creatinina, sodium and potassium measurement; abdominal ultrasound scan; scintigraphy and histological analysis were performed in all animals. Results: In group 3 there was a progressive increase of urea $(p=0.0001)$, creatinine $(p=0.0001)$, sodium $(p=0,0002)$ and potassium $(p=0,0003)$. The comparison of these results with those one of the Groups 1 and 2 , in all intervals, revealed blood rising with statistical significant level $(p<0,05)$. In Group 3, the ultrasound scan identified an increasing of the left kidney size, after 16 weeks and at the 4th week the scintigraphy confirmed the loss of $75 \%$ of the left renal mass. In the same group, the histological evaluation showed subcapsular and intersticial fibrosis and also tubular regeneration. Conclusion: The experimental model of IRC is feasible, with animal's survival in middle term which allows the use of this interval like a therapeutic window for testing different approaches in order to repair the kidney damages.
\end{abstract}

Key words: Models, animal. Surgery. Renal insufficiency. Chronic disease. Rabbits.

\section{REFERÊNCIAS}

1. Ausiello D, Goldman CL. Tratado de medicina interna. $22^{\mathrm{a}}$ ed. Rio de Janeiro: Elsevier - Campus; 2005.

2. Stephan P, DiBartola. Abordagem clínica e laboratorial da afecção renal. In: Ettinger SJ, Feldman EC. Tratado de medicina interna veterinária. $4^{a}$ ed. São Paulo: Manole; 1997. p. 2355 -72.

3. Confer AW, Pancieira RJ. Sistema urinário. In: Carlton WW, McGavin MD. Patologia veterinária especial de Thomson. $2^{a}$ ed. São Paulo: ArtMed; 1998. p. 228-60.
4. Gallangher NI, McCarthy JM, Lange RD. Erythropoietin production in uremic rabbits. J Lab Clin Med. 1961; 57(2):281-9.

5. Bas S, Bas A, Estepa JC, Mayer-Valor R, Rodriguez M, AguileraTejero E. Parathyroid gland function in the uremic rabbit. Domest Anim Endocrinol. 2004; 26(2):99-110.

6. Netto Jr NR. Urologia prática. $4^{a}$ ed. São Paulo: Atheneu; 1999.

7. Kaufman JM, DiMeola HJ, Siegel NJ, Lytton B, Kashgariam M, Hayslett JP. Compensatory adaptation of structure and function following progressive renal ablation. Kidney Int. 1974; 6(1):10-7. 
8. Vercauteren SR, Ysebaert DK, Greef KE, Eyskens E, De Broe ME. Chronic reduction in renal mass in the rat attenuates ischemia/ reperfusion injury and does not impair tubular regeneration. J Am Soc Nefrol. 1999; 10(12):2551-61.

9. Garber SL, Mirochnik Y, Brecklin C, Slobodskoy L, Arruda JA, Dunea G. Effect of relaxin in two models of renal mass reduction. Am J Nephrol. 2003; 23(1):8-12.

10. Kang DH, Yu ES, Yoo K, Johnson R. The impact of gender on progression of renal disease: potential role of estrogen-mediated vascular endothelial growth factor regulation and vascular protection. Am J Pathol. 2004; 164(2): 679-88.

11. Kale S, Karihaloo A, Clark PR, Kashgariam M, Krause DS, Cantley LG. Bone marrow stem cells contribute to repair of the ischemically injured renal tubule. J Clin Invest. 2003; 112 (1):42-9. Epub 2003 Jun 16.

12. Kim KH, Kim Y, Park HW, Jeong HJ, Mauer M. A re-evaluation of the renal ablation model of progressive renal disease in rats. J Nephrol. 2003; 16(2):196-202.

13. Park HW, Kim Y, Kim HK, Jeong HJ, Sbin MH, Rozen S, Mauer M. Angiotensin II receptor blockade blocker pre-treatment largely prevents injury from gradual renal ablation in rats. J Renin Angiotensin Aldosterone Syst. 2007; 8(3):110-7.

14. Schwartz MM, Bidani AK, Lewis EJ. Glomerular epithelial cell function and pathology following extreme ablation of renal mass. Am J Pathol. 1987; 126(2):315-24.

15. Chamberlain RM, Shirley DG. Time course of the renal functional response to partial nephrectomy: measurements in conscious rats. Exp Physiol. 2007; 92(1):251-62. Epub 2006 Nov 3.

16. Chang D, Seo M, Choi H, Lee H, Lee K, Eom K, Lee Y, Yoon J. Application of transarterial embolization of renal artery in rabbits with experimental hydronephrosis. J Vet Med Sci. 2002; 64(8):693-8.

17. Lin F, Cordes K, Li L, Hood L, Couser WG, Shankland SJ, Igarashi P. Hematopoietic stem cells contribute to the regeneration of renal tubules after renal ischemia-reperfusion injury in mice. J Am Soc Nephrol. 2003; 14(5):1188-99.
18. Nakamura N, Masuda S, Takahashi K, Saito H, Okuda M, Inui KI. Decreased expression of glucose and peptide transporters in rat remnant kidney. Drug Metab Pharmacokinet. 2004; 19(1):1-47.

19. Santos LS, Chin EW, loshii SO, Tambara Filho R. Surgical reduction of the renal mass in rats: morphologic and functional analysis on the remnant kidney. Acta Cir Bras. 2006; 21(4):252-7.

20. Ots M, Machenzie HS, Troy JL, Rennke HG, Brenner BM. Effects of combination therapy with enalapril and losartan of the rate of progression of renal injury in rats with 5/6 renal mass ablation. J Am Soc Nephrol. 1998; 9(2):224-30.

21. Totsune K, Mackenzie HS, Totsune H, Troy JL, Lytton J, Brenner BM. Upregulation of atrial natriuretic peptide gene expression on remnant kidney of rats with reduced renal mass. J Am Soc Nephrol. 1998; 9(9):1613-9.

22. Griffin KA, Picken M, Bidani AK. Method of renal mass reduction is a critical modulator of subsequent hypertension and glomerular injury. J Am Soc Nephrol. 1994; 4:(12) 2023-31.

23. Fitzgibbon WR, Greene EL, Grewal JS, Hutchison FN, Self SE, Latten SY, Ullian M. Resistance to remnant kidney in the Wistar-Furth rat. J Am Soc Nephrol. 1999; 10(4):814-21.

Recebido em 08/08/2008

Aceito para publicação em 20/10/2008

Conflito de interesse: Nenhum

Fonte de Financiamento: FAPERJ

\section{Como citar este artigo:}

Costa AF, Pereira LP, Ferreira ML, Silva PC, Chagar VL, Schanaider A. Modelo cirúrgico de insuficiência renal crônica. Estudo em coelhos. Rev Col Bras Cir. [periódico na Internet] 2009; 36(1). Disponível em URL: http://www.scielo.br/rcbc

\section{Endereço para correspondência:}

Andrei Ferreira Nicolau da Costa

E-mail:vetcosta@gmail.com 